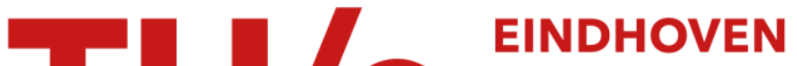 UNIVERSITY OF TECHNOLOGY
}

\section{Automated quantification of human left ventricular deformation with magnetic resonance cardiac tagging}

\section{Citation for published version (APA):}

Aelen, F. W. L., Arts, M. G. J., Sanders, D. G. M., Thelissen, G. R. P., Muijtjens, A. M. M., Prinzen, F. W., \& Reneman, R. S. (1995). Automated quantification of human left ventricular deformation with magnetic resonance cardiac tagging. In A. Murray, \& R. Arzbaecher (Eds.), Computers in cardiology : 22nd IEEE conference : proceedings, Vienna, Austria, 1995 (pp. 629-632). Institute of Electrical and Electronics Engineers.

Document status and date:

Published: 01/01/1995

\section{Document Version:}

Publisher's PDF, also known as Version of Record (includes final page, issue and volume numbers)

\section{Please check the document version of this publication:}

- A submitted manuscript is the version of the article upon submission and before peer-review. There can be important differences between the submitted version and the official published version of record. People interested in the research are advised to contact the author for the final version of the publication, or visit the $\mathrm{DOI}$ to the publisher's website.

- The final author version and the galley proof are versions of the publication after peer review.

- The final published version features the final layout of the paper including the volume, issue and page numbers.

Link to publication

\section{General rights}

Copyright and moral rights for the publications made accessible in the public portal are retained by the authors and/or other copyright owners and it is a condition of accessing publications that users recognise and abide by the legal requirements associated with these rights.

- Users may download and print one copy of any publication from the public portal for the purpose of private study or research.

- You may not further distribute the material or use it for any profit-making activity or commercial gain

- You may freely distribute the URL identifying the publication in the public portal.

If the publication is distributed under the terms of Article $25 \mathrm{fa}$ of the Dutch Copyright Act, indicated by the "Taverne" license above, please follow below link for the End User Agreement:

www.tue.nl/taverne

Take down policy

If you believe that this document breaches copyright please contact us at:

openaccess@tue.nl

providing details and we will investigate your claim. 


\title{
Automated Quantification of Human Left Ventricular Deformation with Magnetic Resonance Cardiac Tagging
}

\author{
FWL Aelen, T Arts, DGM Sanders, GRP Thelissen, AMM Muijtjens, FW Prinzen, RS Reneman \\ Cardiovascular Research Institute Maastricht, Maastricht, The Netherlands
}

\begin{abstract}
A method was developed to quantify deformation of the human cardiac left ventricle (LV) non-invasively. Our primary interest was $L V$ torsion and contraction during the ejection phase, as these may be of clinical importance.

Magnetic Resonance cardiac tagging was used in 9 healthy volunteers to determine displacement, rotation and contraction of two parallel short-axis cross-sections in the $L V$ equatorial region. Rotation angles from these crosssections were subtracted to quantify torsion. During ejection torsion increased by $5.3 \pm 1.2$ degrees (mean \pm sd), and the inner and outer radii decreased from $24.5 \pm 1.7 \mathrm{~mm}$ to $16.8 \pm 1.8 \mathrm{~mm}$, and from $35.7 \pm 2.9 \mathrm{~mm}$ to $31.8 \pm 2.6$ $m m$, respectively.

It can be concluded that the developed method provides a highly automated means for assessment of $L V$ torsion and contraction in humans.
\end{abstract}

\section{Introduction}

The pattern of $L V$ deformation is sensitive to various cardiac disorders, such as myocardial ischemia, cardiac infarction, and hypertrophic cardiomyopathy $[1,2]$. Quantitative assessment of this deformation pattern could therefore be a useful diagnostic tool. Two essential modes of $\mathrm{LV}$ deformation are torsion and contraction. Torsion is associated with rotation of the apex with respect to the base around the long axis of the LV. Global contraction can be described by time courses of the inner and outer radii of $L V$ short-axis cross-sections.

Magnetic Resonance (MR) cardiac tagging [3-5], based on Spatial Modulation of the Magnetization (SPAMM), is a non-invasive method to attach a grid of tags to the myocardium. By following the motion of the grid, deformation of the $\mathrm{LV}$ can be quantified during contraction (figure 1). Methods to quantify grid motion generally rely on a large amount of user-interaction [1, 5-8]. For a useful clinical application it is desirable that tags can be followed in time without interference by an operator. Furthermore, the large amount of motion information should be reduced to a few interpretable quantities.

Our goal was to develop a highly automated method to quantify torsion and contraction of the LV non-invasively with the use of MR cardiac tagging. Tag detectability was enhanced by spatial bandpass filtering. Subsequently the filtered images were thresholded, allowing individual tags to be followed in time. Tracks of the tags were fitted to a kinematic model discerning cross-sectional displacement, rotation and contraction. Rotation angles from two crosssections were subtracted to quantify torsion.

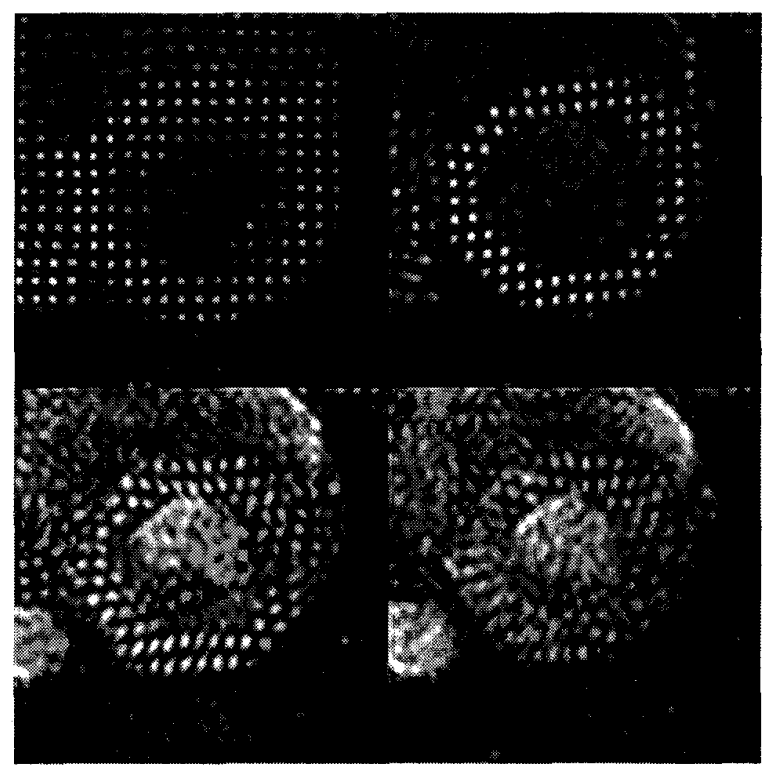

Figure 1. MR-tagged left ventricular short-axis images, $20,96,172$, and $248 \mathrm{~ms}$ after R-wave in ECG (left to right, top to bottom). The motion of tags corresponds to myocardial deformation. Gradually the tags fade away.

\section{Methods}

\subsection{Image acquisition}

Magnetic Resonance Imaging of the LV was performed on 9 healthy volunteers using a 0.5 Tesla MR imaging 
system (Philips Gyroscan T5-II, Philips Medical Systems, Best, The Netherlands). The electrocardiogram (ECG) was used for triggering of image acquisition. The location and orientation of the LV were determined by a compound angulation method. Two parallel short-axis cross-sections were imaged, located about 2 and $4 \mathrm{~cm}$ below the LV base. From both cross-sections two sequential imaging series, partially overlapping in time, were acquired in order to cover the entire ejection phase. Image acquisition of the first series started $20 \mathrm{~ms}$ after detection of the R-wave in the ECG. Acquisition of the second series started during mid-ejection, the precise moment depending on the visually assessed image quality during the first imaging series. The time interval between consecutive images was $20 \mathrm{~ms}$. A field of view of 213 $\mathrm{mm}$ was used at an image resolution of $256 \times 256$ pixels. Slice thickness was $8 \mathrm{~mm}$. Images were obtained by averaging over 4 repeated cardiac cycles. The echo time was $10 \mathrm{~ms}$ and the radiofrequency pulse flip angle for tagging was $40^{\circ}$. Tags were excited in a rectangular grid pattern with an intertag distance of $5 \mathrm{~mm}$. To facilitate image analysis, a $128 \times 128$ pixel region of interest was magnified to $256 \times 256$ pixels by adding zeros to the spatial frequency spectrum.

\subsection{Quantification of $\mathrm{LV}$ deformation}

Tag visibility was enhanced by spatial bandpass filtering. The bandpass filter was tuned to specifically pass the grid of tags. Small deviations in the spatial frequency of the grid were also allowed to pass, thus guaranteeing conservation of cardiac deformation information. Subsequently, the images were thresholded. Examples of a filtered and a thresholded image are shown in figure 2 .

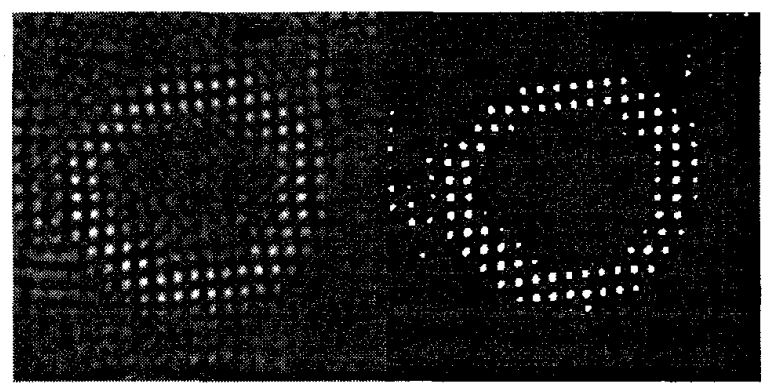

Figure 2. Filtered (left) and thresholded (right) images, 96 ms after R-wave in ECG. Filtering enhanced the detectability of the tags, making thresholding feasible.

The position of a tag was calculated as its center of gravity in the thresholded image. Corresponding tags in consecutive images were found using the Iterative Lower
Rank Approximation procedure developed by Muijtjens et. al. [9]. This procedure also extrapolated coordinates of missing tags in the tag tracks by assuming that all tags follow tracks with a high mutual correlation.

Tag tracks were fitted to a kinematic model of LV cross-sectional deformation. During contraction shortening of base to apex segment length was taken to be $65 \%$ of outer circumference shortening [10]. Then, assuming constant LV wall volume, the radial motion of all points in a cross-section of the wall is determined by the outer radius. Using the measured tracks of all individual tags, changes in the outer radius were estimated. Besides the outer radius, displacement and rotation of the LV cross-section were included in the kinematic model. The motion parameters in the kinematic model were estimated with respect to a reference time that was quite arbitrarily chosen to be in mid-ejection. Starting from the tag positions at the reference time, initial estimates of the motion parameters were applied to calculate tag positions at time t. Differences between thus calculated tag positions and measured tag positions at time $t$ were minimized by changing the parameter values following Powell's method [11]. Note that both imaging series partially overlapping in time were processed independently, each with its own reference tag positions. The reference time, however, was the same for all imaging series.

The LV inner and outer radii were estimated visually from the images at a reference time. Changes in the outer radius throughout the ejection phase were estimated in the kinematic model. Using the inner radius at the reference time and the outer radii at all times, the inner radii could also be calculated at all times, assuming constant LV wall volume. LV torsion was calculated as rotation of the lower cross-section with respect to the upper crosssection.

\section{Results}

Images were acquired from 9 healthy volunteers at two parallel short-axis cross-sections located in the LV equatorial region.

Rotation from the beginning to the end of ejection was on average $-3.2 \pm 2.8$ degrees (mean \pm sd) for the upper

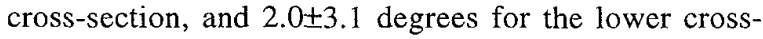
section. Time courses of rotation angles are shown in figure 3. Rotation angles of the upper cross-section were subtracted from rotation angles of the lower cross-section to calculate torsion (figure 4). During ejection torsion increased by an amount of $5.3 \pm 1.2$ degrees.

The outer radius decreased from $36.0 \pm 2.7 \mathrm{~mm}$ to $32.3 \pm 2.7 \mathrm{~mm}$ for the upper cross-section, and from $35.4 \pm 3.0 \mathrm{~mm}$ to $31.4 \pm 2.5 \mathrm{~mm}$ for the lower cross- 
section. The decreases in inner radii were relatively larger: from $25.2 \pm 1.5 \mathrm{~mm}$ to $18.1 \pm 2.2 \mathrm{~mm}$, and from $23.9 \pm 2.1$ $\mathrm{mm}$ to $15.5 \pm 2.0 \mathrm{~mm}$ for the upper and the lower crosssection, respectively. Time courses of these radii are shown in figure 5.

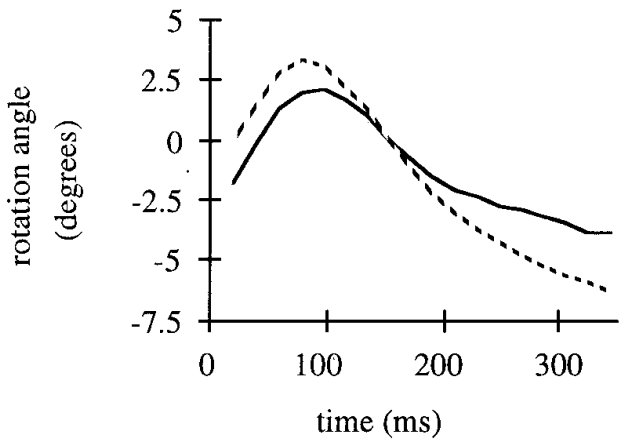

Figure 3. Time courses of the rotation angles of the lower (solid line) and the upper (dashed line) LV cross-sections. Time zero refers to the R-wave in the ECG.

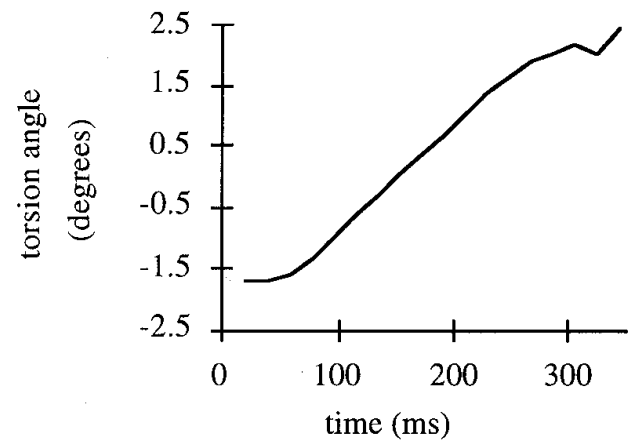

Figure 4. Torsion angle as a function of time.

The time required for the entire analysis of the images was approximately 15 minutes on a SUN Sparc IPX, manual actions being limited to visual determination of the LV center and inner and outer radii at the reference time.

\section{Discussion}

A highly automated method was developed to quantify LV deformation with a few deformation parameters. Our primary interest was determination of torsion and contraction of the LV during the ejection phase. Torsion and contraction have been studied extensively [5, 12-14]. Cardiac disorders such as ischemia, infarction, and hypertrophic cardiomyopathy have been shown to alter the myocardial deformation pattern $[1,2]$. Therefore, torsion and contraction during the ejection phase may be of clinical importance. A clinical application of a method to determine LV deformation desires a high degree of

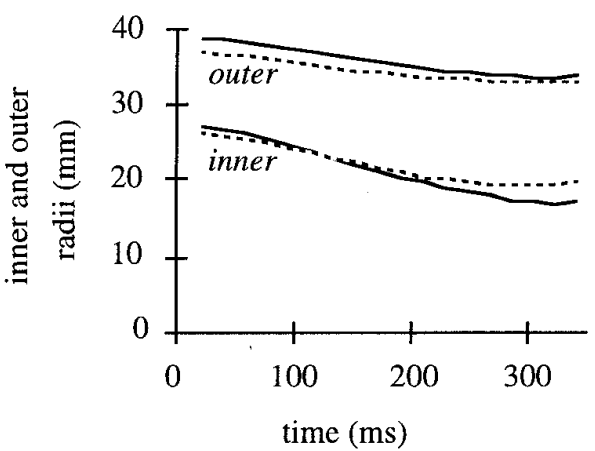

Figure 5. Time courses of the inner and outer radii of the lower (solid line) and the upper (dashed line) LV crosssections.

automation. Most of the existing methods based on MR cardiac tagging require a substantial amount of userinteraction. Our method, however, satisfies the demand for automation. The user is only required to give an estimate of the LV inner and outer radii at a reference time, and a rough estimate of the LV center at that time. Then, for both cross-sections, the inner and outer radii, the LV centers, and the rotation angles are estimated by the kinematic model for all times.

Thresholding of the filtered images and the representation of the position of a tag by its center of gravity in the thresholded image enable the high degree of automation. Bandpass filtering of the images made thresholding feasible. The bandwidth of the spatial bandpass filter allowed passing of perturbations of the grid due to strains in a cross-section of the LV wall of maximally $30 \%$, and rotations of less than 20 degrees. As a result high frequency noise and low frequencies, responsible for the relatively large bright areas in the LV cavity, were filtered out.

Inner and outer radii of the LV could be determined visually from gradient-echo MR images with an accuracy of about $\pm 1 \mathrm{~mm}$. Changes in these radii are in the same order of magnitude and can therefore not be assessed visually with a high enough reliability. We estimated the inner and outer radii only at a reference time by visual assessment, changes in the radii were determined by the kinematic model. These calculated changes were based on the motion of all detected tags in a cross-section of the myocardial wall. Thus determined radii at all times were within the limits of accuracy with which the radii could be determined visually. The changes in radii, however, were determined with a much higher accuracy.

Torsion angles vary with the distance between two cross-sections. The shear angle on the epicardium, calculated as the torsion angle multiplied by the outer radius and divided by the distance between the two cross- 
sections, is more or less independent of this distance [5]. Buchalter et. al. [5] found an average epicardial shear angle from the beginning of ejection to end ejection of 5.0 \pm 0.6 degrees for 8 normal volunteers, while Arts et. al. [14] found a shear angle of about 7 degrees in the dog. These values are compatible with the angle of $8.4 \pm 1.5$ degrees found in the present study.

Displacements of individual tags were quantified by our method. Although it was not of our primary interest here, residual errors from the globally calculated motion parameters could also be determined for each tag. Therefore, the method could also be used to investigate regional differences in torsion and contraction. The spatial resolution, however, is limited by the intertag distance of $5 \mathrm{~mm}$, i.e., there are only about 2 or 3 tags across the wall.

To automatically follow tags during the whole ejection phase it was essential to have two sequential imaging series at each cross-section. If manual interventions were allowed one imaging series could suffice. An advantage of our method, however, is that it is capable of a faster and more objective means of assessment of tag positions than would be possible manually.

We only considered displacement, contraction, and torsion of the LV. In the ejecting LV, however, the deformation pattern is more complex. Other deformation modes can be included in the kinematic model to describe the deformation pattern more accurately.

It can be concluded that the developed method provides a highly automated means for assessment of LV torsion and contraction in humans.

\section{References}

[1] Maier SE, Fischer SE, McKinnon GC, Hess OM, Krayenbuehl HP, and Boesiger P. Evaluation of Left Ventricular Segmental Wall Motion in Hypertrophic Cardiomyopathy with Myocardial Tagging. Circulation 1992;86:1919-1928.

[2] Prinzen FW, Arts T, Hoeks APG, and Reneman RS. Discrepancies between Myocardial Blood Flow and Fiber Shortening in the Ischemic Border Zone as assessed with Video Mapping of Epicardial Deformation. Eur J Physiol 1989;415:220-229.

[3] Zerhouni EA, Parish DM, Rogers WJ, Yang A, and Shapiro EA. Human Heart: Tagging with MR Imaging A Method for Noninvasive Assessment of Myocardial Motion. Radiology 1988;169:59-63.

[4] Axel L, and Dougherty L. MR Imaging of Motion with Spatial Modulation of the Magnetization. Radiology $1989 ; 171: 841-845$
[5] Buchalter MB, Weiss JL, Rogers WJ, Zerhouni EA, Weisfeldt ML, Beyar R, et al. Noninvasive Quantification of Left Ventricular Rotational Deformation in Normal Humans Using Magnetic Resonance Imaging Myocardial Tagging. Circulation 1990;81:1236-1244.

[6] Clark NR, Reichek N, Bergey P, Hoffman EA, Brownson $D$, Palmon $L$, et al. Circumferential Myocardial Shortening in the Normai Human Left Ventricle Assessment by Magnetic Resonance Imaging Using Spatial Modulation of Magnetization. Circulation 1991;84:67-74.

[7] Young AA, Imai $\mathrm{H}$, Chang $\mathrm{CN}$, and Axel L. Twodimensional Left Ventricular Deformation during Systole using Magnetic Resonance Imaging with Spatial Modulation of Magnetization. Circulation 1994;89:740-752.

[8] Qi P, Thomsen C, Ståhlberg F, and Henriksen O. Normal Left Ventricular Wall Motion Measured with Twodimensional Myocardial Tagging. Acta Radiol 1993;34(5):450-456.

[9] Muijtjens AMM, Roos JMA, Arts T, Hasman A, and Reneman RS. Extrapolation of Incomplete Marker Tracks by Lower Rank Approximation. Int J Biomed Comput 1993;33:219-239.

[10] Feigl EO, and Fry DL. Intramural myocardial shear during the cardiac cycle. Circ Res 1964;14:536-540.

[11] Press WH, Flannery BP, Teukolsky SA, and Vetterling WT. Numerical recipes - The art of scientific computing. Cambridge: Cambridge University Press, 1988.

[12] Hansen DE, Daughters GT, Alderman EL, Ingels NB, Stinson EB, and Miller DC. Effect of volume loading, pressure loading, and inotropic stimulation on left ventricular torsion in humans. Circulation 1991;83:1315-1326.

[13] Young AA, Kramer CM, Ferrari VA, Axel L, and Reichek N. Three-dimensional left ventricular deformation in hypertrophic cardiomyopathy. Circulation 1994;90:854-867.

[14] Arts T, Meerbaum S, Reneman RS, and Corday E. Shear of the left ventricle during the ejection phase in the intact dog. Cardiovasc Res 1984;18:183-193.

Address for correspondence.

Theo Arts, PhD

Department of Biophysics

Cardiovascular Research Institute Maastricht

University of Limburg

P.O. Box 616

$6200 \mathrm{MD}$ Maastricht

The Netherlands

email: Frank.Aelen@Bf.Rulimburg.Nl 